J. Lake Sci.(湖泊科学), 2008, 20(5): 681-686 http://www.jlakes.org. E-mail: jlakes@niglas.ac.cn (C)2008 by Journal of Lake Sciences

\title{
云南抚仙湖透明度的时空变化及影响因子分析*
}

\author{
潘继征 ${ }^{1,2}$, 熊 飞 ${ }^{2,3}$, 李文朝 ${ }^{1}$, 李荫梏 ${ }^{4}$ \\ (1: 中国科学院南京地理与湖泊研究所湖泊与环境国家重点实验室，南京 210008) \\ (2: 中国科学院研究生院, 北京 100049) \\ (3: 江汉大学, 武汉 430056) \\ (4: 玉溪市环境监测站，玉溪 653100)
}

摘 要: 根据 2005 年的综合调查资料和 1980 年以来的常规监测资料, 分析了云南高原深水湖泊抚仙湖透明度的空间分布、 年际变化及影响因子. 2005 年 6-7 月抚仙湖水体透明度范围为 0.5-6.2 m, 平均值为 $4.6 \mathrm{~m}$, 透明度分布的总体格局是: 南区> 北区, 湖心区>沿岸区, 河口区较低. 藻类和悬浮物是影响透明度空间分布的主要因子, 随着水体中藻类和悬浮物的增加, 透 明度下降. 近 20 多年来, 抗仙湖透明度呈下降趋势, 藻类增加是直接影响因子, 水体总氮、总磷的增加促进了藻类的增殖, 是 重要的间接影响因子.

关键词: 抚仙湖; 水体透明度; 时空变化; 藻类

\section{Spatial-temporal dynamic changes of the water transparency and their influencing factors in Lake Fuxian, Yunnan Province}

\author{
PAN Jizheng ${ }^{1,2}$, XIONG Fei ${ }^{2,3}$, LI Wenchao ${ }^{1} \&$ LI Yinxi ${ }^{4}$ \\ (1: State Key Laboratory of Lake Science and Environment, Nanjing Institute of Geography and Limnology, Chinese Academy of \\ Sciences, Nanjing 210008, P.R.China) \\ (2: Graduate School of Chinese Academy of Sciences, Beijing 100049, P.R.China) \\ (3: Academy of Development, Jianghan University, Wuhan 430056, P.R.China) \\ (4: Yuxi Environmental Monitoring Station, Yuxi 653100, P.R.China)
}

Abstract: The spatial distribution, temporal changes of water transparency and their influencing factors in Lake Fuxian, a deep lake in Yunnan Plateau, were analyzed according to the investigations during June-July in 2005 and the regular monitoring data since 1980. The Secchi disk transparency varied from $0.5-6.2 \mathrm{~m}$ with an average value of $4.6 \mathrm{~m}$ in Lake Fuxian during June-July in 2005 , The spatial distribution pattern of transparency was: north area<south area, littoral zone<pelagic zone, and very low in the estuary area. Suspended solid and algae were the main influencing factors on spatial distribution of water transparency which decreased with their increase. In the last 20 more years, water transparency in Lake Fuxian showed decrease trend, and the increase of algae was the main direct influencing factor. The increase of total nitrogen and total phosphorous was the important indirect influencing factors which could lead to algae multiplication.

Keywords: Lake Fuxian; water transparency; spatial-temporal dynamic changes; algae

透明度 $(\mathrm{SD})$ 是水体能见程度的一个量度, 也是评价水体富营养化的一个重要指标 ${ }^{[1]}$. 透明度的下降, 会直接影响沉水植物和其他水生生物的生存, 从而导致湖泊生态系统的恶性循环, 加速湖泊富营养化趋 势的发展. 因此，研究透明度的时空变化，探求影响透明度下降的主导因子和有效的对策措施，在湖泊 生态保护和富营养化防治中具有重要意义. 一般认为, 藻类、悬浮物和溶解性有机物是几个常见的影响

* 国家 863 项目(2005AA60101004)资助. 2007-12-06 收稿; 2008-05-22 收修改稿. 潘继征, 男, 1975 年生, 助理研究员;

E-mail: jzhpan@niglas.ac.cn. 
因子 ${ }^{[2]}$, 而对不同的湖泊水体, 每个因子的影响程度可能不同, 如悬浮物是太湖透明度的主要影响因

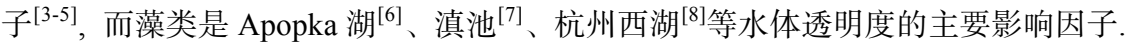

抚仙湖位于云南高原中部, $24^{\circ} 21^{\prime} 28^{\prime \prime}-24^{\circ} 38^{\prime} 00^{\prime \prime} \mathrm{N}, 102^{\circ} 49^{\prime} 12^{\prime \prime}-102^{\circ} 57^{\prime} 26^{\prime \prime} \mathrm{E}^{[9]}$, 是我国著名的高原深 水断陷湖泊，不仅具有独特的生物资源，而且蕴藏着珍贵的水资源和旅游资源，是湖区社会经济发展的 重要物质基础. 抚仙湖透明度曾高达 10 多米 ${ }^{[10]}$, 但近 20 多年来, 随着湖区人类活动压力的迅速增加, 水 污染日益加剧, 湖泊生态环境正在发生剧烈变化, 透明度的下降表现得非常突出 ${ }^{[11]}$. 对我国湖泊透明度 影响因子的研究, 多见于浅水湖泊, 而对高原深水湖泊透明度下降原因的探讨, 少见报道. 本研究通过 现场调查和常规监测资料的分析，研究了抚仙湖透明度的空间分布、年际变化及影响因子，旨在探求高 原深水湖泊透明度下降的机理, 为研究高原深水湖泊富营养化发生机理积累资料, 为湖泊治理和管理提 供科学依据。

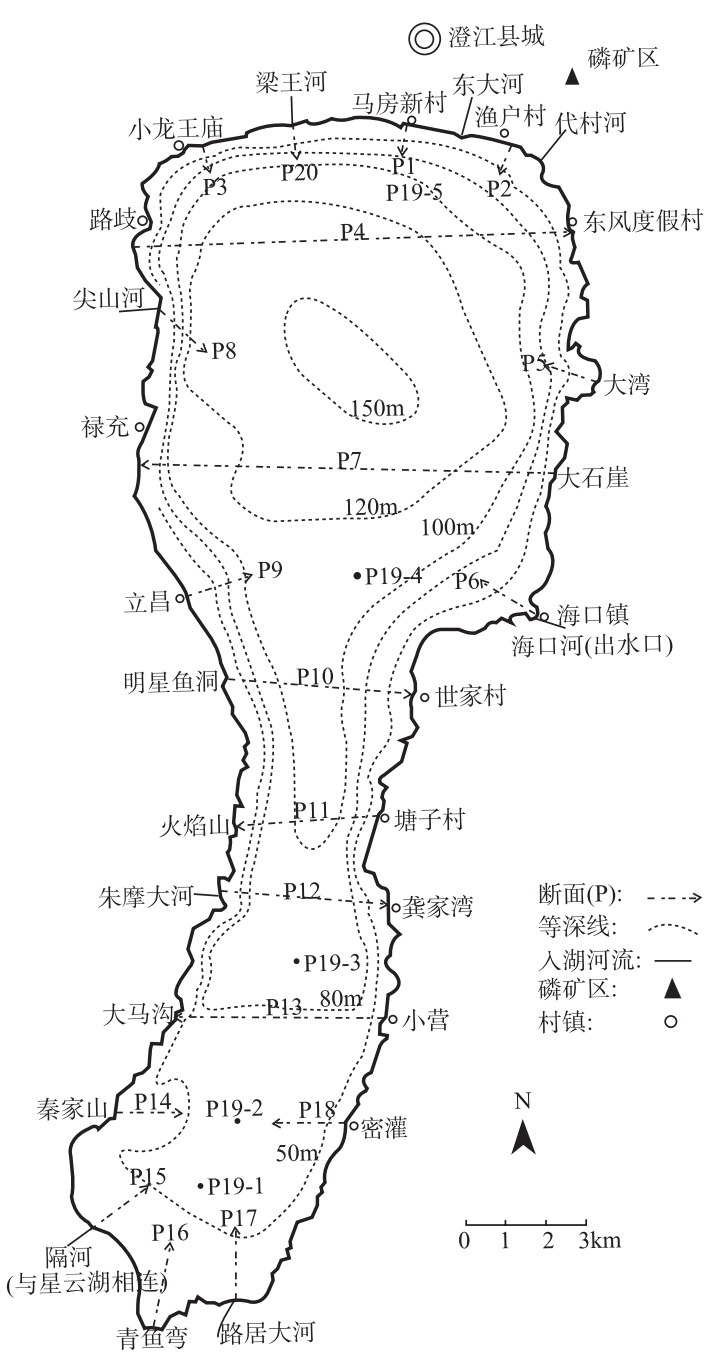

图 1 抚仙湖采样点分布

Fig.1 Map of sampling location of Lake Fuxian

\section{1 研究方法}

\section{1 样点设置和调查项目}

2005 年 6-7 月对抚仙湖水体透明度情况 进行了调查, 使用 NAVCOM SF-2050 导航定 位. 根据抚仙湖的形态特点, 全湖共设 20 个 断面, 累计 119 个样点(图 1). 其中 P19 为从 南至北的纵向断面, 共有 5 个样点; P4、P7、 P10-13 为贯穿东西的横向断面, 其余为从岸 边至离岸 $1 \mathrm{~km}$ 的垂直于岸线方向断面, 每个 断面 6 个样点, 根据断面长度均匀分布. 调 查项目包括水深、透明度、叶绿素 $\mathrm{a}$ 、悬浮 物、总氮、总磷、溶解性总氮、溶解性总磷、 藻类及表层沉积物的总有机碳、总氮和总磷 等.

\section{2 采样和分析方法}

每个样点用测绳和 RBR XR-620 深水水 质剖面仪测量水深，用赛克盘(Secchi disc)测 量透明度. 用 $25 \mathrm{~L}$ 柱状采水器采水, 水样为 距表层 0.5-1.5m(通过 RBR XR-620现场观测, 为藻类和悬浮物的主要集中区域)的混和水 样, 不同点位的采样层次均一致, 在水上工 作平台上现场分样和预处理. 取 0.5-2L 水样 用 $0.45 \mu \mathrm{m}$ 微孔滤膜过滤藻类, 用于提取和测 定叶绿素 a(Chl.a); 取 0.5-1L 水样用 $0.45 \mu \mathrm{m}$ 微孔滤膜过滤悬浮物质，用于分析悬浮物; 取 $1 \mathrm{~L}$ 水样置于冰盒内保存, 用于测定总氮、 总磷、溶解性总氮、溶解性总磷; 取 $1 \mathrm{~L}$ 水样, 立即加 $15 \mathrm{ml}$ 鲁哥氏液固定，作为藻类定量 样品.

水质分析方法参考《水和废水监测分析 方法(第四版) $\rangle^{[12]}$ (表 1).

\section{3 统计分析}

1980-2004 年水质数据来源于玉溪市环境监测站的常规监测资料, 全湖共设马房新村、湖心、尖山和 
路居 4 个固定监测点, 每年枯、丰和平水期各监测 2 次, 取平均值. 数据的分析处理使用 Excel 和 SPSS 软 件.

分区. 2005 年采样时, 断面 P1-P9, P20 及样点 P19-4 和 P19-5 分布在北区; 断面 P10-P18 及样点 P19-1-P1-3 分布在南区; 岸距 $<1000 \mathrm{~m}$ 的样点归为沿岸带, 岸距 $\geqslant 1000 \mathrm{~m}$ 的样点归为湖心区.

表 1 测试项目及分析方法

Tab.1 Items and their analysis methods

\begin{tabular}{|c|c|}
\hline 测试项目 & 分析方法 \\
\hline 总氮(TN) & 过硫酸钾氧化一紫外分光光度法 \\
\hline 总磷(TP) & 过硫酸钾消解－锄锑抗分光光度法 \\
\hline 溶解性总氮(TDN) & $0.45 \mu \mathrm{m}$ 滤膜过滤, 过硫酸钾氧化一紫外分光光度法 \\
\hline 溶解性总磷(TDP) & $0.45 \mu \mathrm{m}$ 滤膜过滤, 过硫酸钾消解一钿锑抗分光光度法 \\
\hline 叶绿素 a(Chl.a) & $90 \%$ 丙酮提取, 分光光度法 \\
\hline 悬浮物(SS) & $0.45 \mu \mathrm{m}$ 滤膜过滤, $103-105^{\circ} \mathrm{C}$ 烘干 \\
\hline 沉积物总有机碳(TOC) & 重铬酸钾一硫酸(油浴)氧化, 硫酸亚铁滴定 \\
\hline 沉积物总氮 $\left(\mathrm{TN}^{\prime}\right)$ & 硫酸一重铬酸钾消化, 凯氏法 \\
\hline 沉积物总磷 $\left(\mathrm{TP}^{\prime}\right)$ & 硫酸一高氯酸酸溶, 钿锑抗比色法 \\
\hline 藻类 & 显微镜计数框读数, 为单位体积中藻类的群体个数 \\
\hline
\end{tabular}

水质指标计算. 根据各水质指标的具体情况，按照一定的间距在 AUTOCAD 电子地图上绘制出其等 值线分布图, 将水体分成若干区域 $i(i=1,2,3 \ldots \ldots . m ; m=5-6)$, 计算出各区域的面积权重 $r_{i}$ 和相应指标的平 均浓度 $C_{i}, C_{i}$ 为落在该区域的样点的算术平均值, 全湖平均浓度 $C$ (加权平均值)的计算公式为:

$$
C=\sum_{i=1}^{m} C_{i} \cdot r_{i}
$$

总氮、总磷和透明度全湖平均值的计算均按照各自的标准先进行分区，悬浮物、叶绿素 $\mathrm{a}$ 以透明度 的分区为依据直接进行计算.

\section{2 结果与讨论}

\section{1 透明度的空间分布}

2.1.1 不同湖区的分布 2005 年 6-7 月水体透明度范围为 0.5-6.2m, 全湖加权平均值为 4.6m, 其中南区为 $5.05 \mathrm{~m}$, 北区为 $4.38 \mathrm{~m}$, 两者差异性显著 $(P<0.01)$. 总体上, 南区大于北区, 湖心区大于沿岸区, 河口区较低.

北区由于滨临澄江坝区，城镇生活污水和农业面源污染比较集中，而东北部大范围的磷矿开采、西 北部严重的水土流失，以及常年盛行的东南风将南部的部分污染物吹向北部湖区，都加剧了北部湖区的 水质污染，而因造成北区的透明度小于南区，北区表层水体总氮、叶绿素 $\mathrm{a}$ 和悬浮物浓度分别为南部湖区 的 1.5 倍、 1.3 倍和 2.5 倍.

透明度最高的区域位于南部湖心偏东岸区域，由于此区域的东岸大都为陡峭的岩石湖岸，居民区较 少, 其他形式的污染如旅游污染也很小, 因此湖水透明度高. 北岸受风浪的冲刷最严重, 加上水体流水 和人湖垃圾杂物的影响, 岸边 $100 \mathrm{~m}$ 范围内的水体为浑浊状态, 透明度明仅为 $1.54 \mathrm{~m}$. 尖山河口水土流失 比较严重, 以河口为中心的较大扇形区域内均为红色的浑浊水体, 在尖山河口 $200 \mathrm{~m}$ 范围内, 悬浮物的含 量为全湖最高, 高达 $21.46 \mathrm{mg} / \mathrm{L}$. 隔河口由于受星云湖泄水蓝藻的影响水体呈绿色, 在隔河口 $200 \mathrm{~m}$ 范围内, 肉眼可见密集的蓝藻颗粒, 群体密度达 $169.75 \times 10^{4} \mathrm{ind} . / \mathrm{L}$, 叶绿素 $\mathrm{a}$ 含量高达 $15.32 \mu \mathrm{g} / \mathrm{L}$, 透明度也很低. 


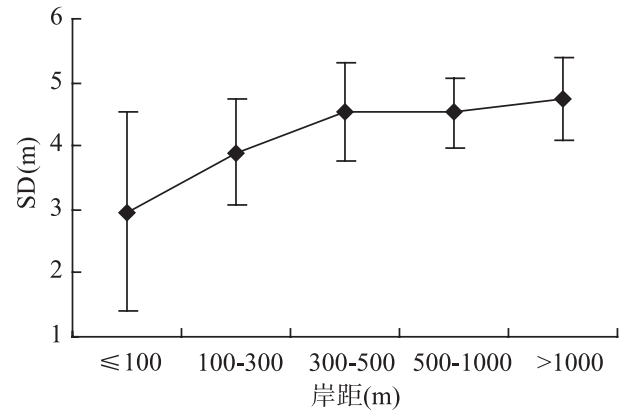

图 2 水体透明度沿岸距的变化

Fig.2 Distribution of SD in different distances to the bank

2.1.2 沿岸距的分布 在 $500 \mathrm{~m}$ 岸距内, 随岸距的增大, 透明度增大, 从 $100 \mathrm{~m}$ 岸距内的 $2.96 \mathrm{~m}$ 增加到 $300-500 \mathrm{~m}$ 范围内的 $4.53 \mathrm{~m}$ ，而在离岸 $500 \mathrm{~m}$ 以外的水域，透明度 趋于稳定，500-1000m 岸距范围内的平均透明度为 $4.53 \mathrm{~m}$, 岸距 $1000 \mathrm{~m}$ 以外的平均透明度为 $4.74 \mathrm{~m}$ (图 2).

\section{2 透明度空间分布的影响因子}

相关分析表明(表 2), 透明度与水深呈显著正相关 $(P<0.001)$, 与悬浮物、总氮、溶解性总氮、总磷、溶解 性总磷、叶绿素 $\mathrm{a}$ 和藻类等呈显著负相关 $(P<0.001)$, 而 与沉积物中的总有机碳、总氮、总磷相关性不显著 $(P>0.05)$. 多元逐步回归分析表明，总氮、藻类和悬浮 物等 3 个因子与透明度的相关性最高. 总氮是藻类生 长繁殖所需的营养物质, 因此可以认为藻类和悬浮物 是影响透明度空间分布的主要因子, 随着水体中藻类和悬浮物的增加, 水体透明度下降(图 3).

表 2 水体透明度与环境因子的线性相关系数

Tab. $2 R^{2}$ statistics of linear regression analysis between SD and environmental factors

\begin{tabular}{|c|c|c|c|c|c|c|c|c|c|c|c|}
\hline & $\begin{array}{l}\text { 水深 } \\
(\mathrm{m})\end{array}$ & $\begin{array}{c}\text { 沉积物 } \\
\text { 总有机碳 } \\
(\mathrm{g} / \mathrm{kg})\end{array}$ & $\begin{array}{c}\text { 沉积物 } \\
\text { 总氮 } \\
(\mathrm{g} / \mathrm{kg})\end{array}$ & $\begin{array}{c}\text { 沉积物 } \\
\text { 总磷 } \\
(\mathrm{g} / \mathrm{kg})\end{array}$ & $\begin{array}{l}\text { 悬浮物 } \\
(\mathrm{mg} / \mathrm{L})\end{array}$ & $\begin{array}{c}\text { 总氮 } \\
(\mathrm{mg} / \mathrm{L})\end{array}$ & $\begin{array}{c}\text { 溶解性 } \\
\text { 总氮 } \\
(\mathrm{mg} / \mathrm{L})\end{array}$ & $\begin{array}{c}\text { 总磷 } \\
(\mathrm{mg} / \mathrm{L})\end{array}$ & $\begin{array}{c}\text { 溶解性 } \\
\text { 总磷 } \\
(\mathrm{mg} / \mathrm{L})\end{array}$ & $\begin{array}{c}\text { 叶绿 } \\
\text { 素 a } \\
(\mu \mathrm{g} / \mathrm{L})\end{array}$ & $\begin{array}{l}\text { 藻类 } \\
\left(\times 10^{4}\right. \\
\text { ind./L) }\end{array}$ \\
\hline$K$ & $0.39^{*}$ & 0.08 & 0.08 & 0.08 & $-0.56^{*}$ & $-0.73^{*}$ & $-0.47^{*}$ & $-0.51^{*}$ & $-0.38^{*}$ & $-0.39^{*}$ & $-0.63^{*}$ \\
\hline$n$ & 112 & 55 & 55 & 55 & 115 & 116 & 116 & 116 & 112 & 116 & 106 \\
\hline
\end{tabular}

*表示相关关系显著 $(P<0.001), n$ : 采样点数.
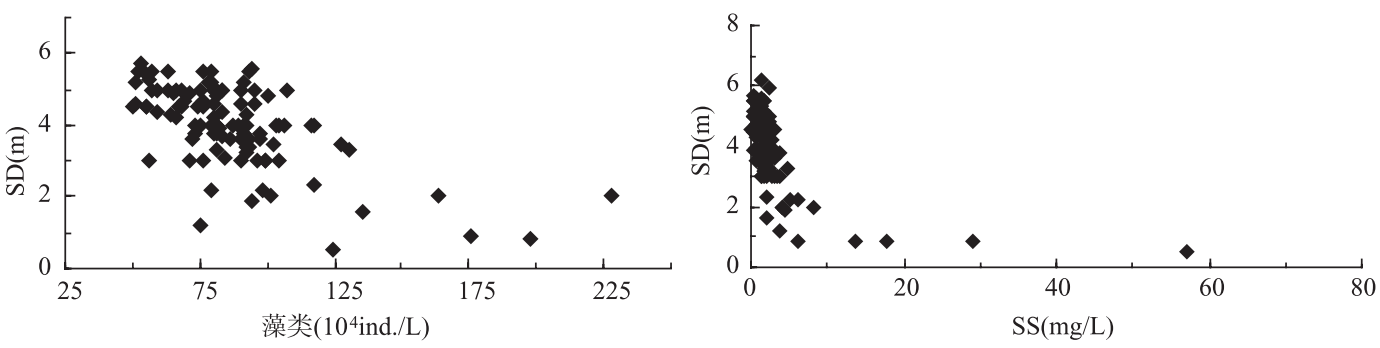

图 3 水体透明度与藻类和悬浮物的关系

Fig.3 Relationship between SD and algae, SS

对于不同区域来说, 透明度的影响因素存在一定差异. 在湖心区域, 泥沙含量少, 悬浮物的主要成 分是藻类, 即藻类是主要影响因素. 而在沿岸浅水区域, 受径流、风浪扰动的影响, 水体普遍浑浊, 透明 度较低, 悬浮物中泥沙等无机颗粒是主要影响因素. 在悬浮物浓度很低时(湖心深水区域), 透明度的变化 范围很大, 即在悬浮物浓度很低时, 悬浮物(主要指无机颗粒物)对透明度的影响不显著, 主要受藻类的影 响(图 3).

\section{3 抚仙湖水体透明度的变化趋势}

1980 年以来, 抚仙湖水体平均透明度持续下降, 从 1980 年平均 $7.9 \mathrm{~m}$ 降低至 2005 年的 $4.6 \mathrm{~m}$ (图 4). 1980-1990 年, 平均每年降低 0.08m；1990-2005 年, 平均每年降低了约 0.21m. 2003 年以来，透明度有一 
定程度的提高, 可能与采取了一系列的水污染治理措施有关, 如取缔机动船, 人湖河流的水质净化、湖滨 带生态修复等. 2005 年 6-7 月抚仙湖水体透明度最大透明度不足 $7 \mathrm{~m}$, 而 1980 年前后最大透明度可达 $10 \mathrm{~m}$ 以上, 不管是从平均值还是范围来看, 抚仙湖透明度的下降趋势都是非常显著的.

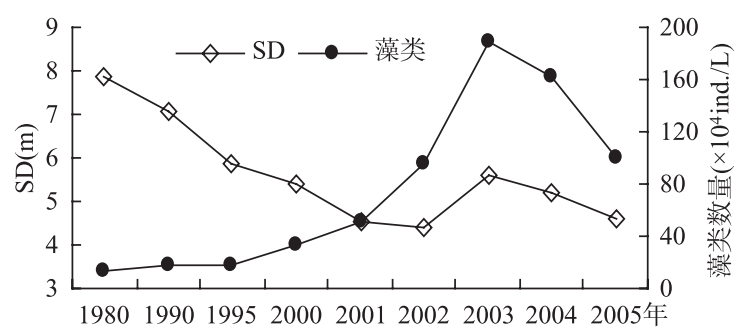

图 4 1980-2005 年抚仙湖水体透明度和藻类的变化趋势

Fig.4 Changing trends of SD and algae in the surface water in Lake Fuxian during 1980-2005

此次调查与 1980 年前后的调查相比，透明度空间分布格局也发生了显著变化. 1980 年前后透明度大 都为 8-11m，而目前大都为 3-6m. 1980 年前后北区的透明度大于南区，而此次调查时南区大于北区. 1980 年前后透明度最大的区域位于尖山头一禄充附近，高达 $11 \mathrm{~m}$, 而随着旅游开发等人类活动的加剧，此区 域水质受到了明显的污染，透明度仅为 3-5m. 1980 年前后，湖区透明度相对较低的区域是北岸和南岸，而 目前透明度较低的区域明显扩大，几乎扩大到了所有沿岸带. 抚仙湖透明度大小及其分布格局的变化，与 水质污染的实际情况是密切相关的，随着人类活动影响的加剧，北区的水质污染比南区突出.

\section{4 透明度下降的影响因子分析}

2.4.1 藻类 藻类是影响水体透明度的主要因素之一. 藻类的大量增殖, 一方面可以增强对光的吸收和散 射, 阻碍光线在水体中传播; 另一方面, 增加光的衰减, 降低水体透明度. 近 20 多年来, 抚仙湖浮游藻类 数量持续增加(图 4), 特别是 2001-2003 年, 藻类数量增长速度显著加快, 在 3 年中藻类数量增加了 3.1 倍. 藻类的增加从而促进透明度的下降, 其与透明度呈显著负相关 $\left(R^{2}=-0.303, P<0.001, n=9\right)$.

2.4.2 悬浮物 水体中悬浮物的增加会增加对光辐射的衰减, 从而降低水体的透明度. 但从抚仙湖悬浮物 的年际变化来看, 1982-2005年悬浮物并没有表现出明显上升趋势，而是具有一定的波动性(图 5). 可以认 为悬浮物并不是导致抗仙湖透明度下降的主要因素.

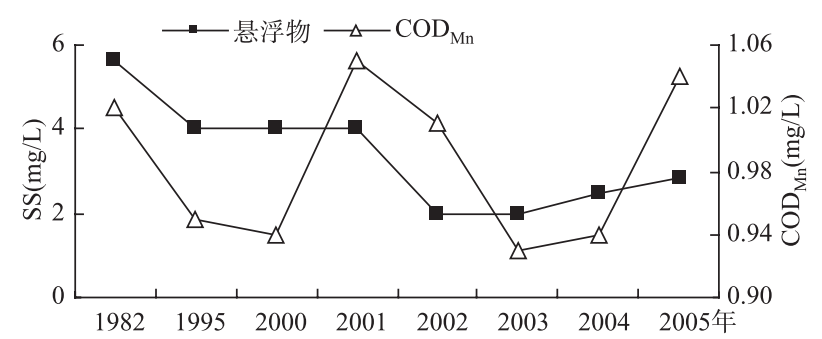

图 5 1982-2005 年抚仙湖水体中悬浮物和 $\mathrm{COD}_{\mathrm{Mn}}$ 的变化趋势

Fig.5 Changing trends of SS and $\mathrm{COD}_{\mathrm{Mn}}$ in Lake Fuxian during 1982-2005

2.4.3 溶解性有机物 水中的溶解性有机物, 特别是有色溶解性有机物对水体光线有很强的吸收, 从而降 低透明度. 由于有色溶解性有机物的化学组成成分复杂, 提取测定困难较大, 本文分析了 $\mathrm{COD}_{\mathrm{Mn}}$ 与透明 度的关系. 1982-2005 年 $\mathrm{COD}_{\mathrm{Mn}}$ 没有明显的上升和下降趋势(图 5), 平均值约为 $0.99 \mathrm{mg} / \mathrm{L}$, 与透明度的相 关性不显著 $(P>0.05)$.

2.4.4 总氮和总磷 近 20 多年来, 抚仙湖水体营养水平不断提高(图 6), 1981-1985 年表层湖水中总氮、总 磷的含量分别为 $0.1 \mathrm{mg} / \mathrm{L}$ 和 $0.005 \mathrm{mg} / \mathrm{L}$ ，而 2001-2005 年总氮、总磷分别增加到 $0.223 \mathrm{mg} / \mathrm{L}$ 和 $0.013 \mathrm{mg} / \mathrm{L}$. 氮、 
磷是藻类生长必须的主要营养元素, 表层湖水中氮、磷含量的增高无疑是引起藻类增长的主要因素, 进而间 接影响到湖水透明度的大小. 1980 年以来, 抚仙湖营养水平逐渐提高, 总氮和总磷显著增长, 对藻类种群数 量起到了明显的促进作用, 2001 年以来平均密度是 1995 年前的 7 倍, 达 $119.25 \times 10^{4} \mathrm{ind}$./L. 1980、1990、2000 和 2005 年抚仙湖的总氮、总磷和藻类密度呈显著正相关 $\left(R^{2}=0.95, P<0.01, n=4 ; R^{2}=0.90, P<0.01, n=4\right)$.

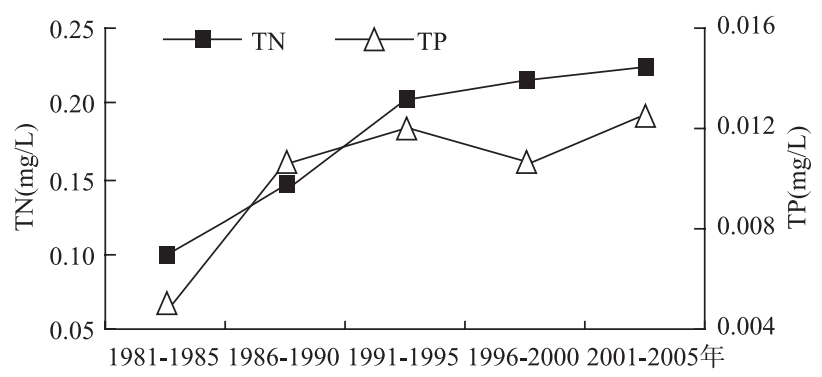

图 6 1981-2005 年抚仙湖水体总氮和总磷的变化

Fig.6 Changing trend of TN and TP in Lake Fuxian during 1982-2005

\section{3 结论}

(1) 2005 年 6-7 月抚仙湖水体透明度范围为 0.5-6.2m, 加权平均值为 4.6m, 总体上, 南区大于北区, 湖心区大于沿岸区, 河口区较低. 在 $500 \mathrm{~m}$ 范围内, 随岸距的增加透明度增大, 在 $500 \mathrm{~m}$ 范围外, 透明度趋 于稳定.

（2）藻类和悬浮物是影响透明度空间分布的主要因子，随着水体中藻类和悬浮物的增加，水体透明 度下降. 在湖心区域, 泥沙含量少, 以藻类影响为主，而在沿岸浅水区域，受径流、风浪扰动的影响，以 悬浮物中的泥沙等无机颗粒影响为主.

(3) 1980 年以来, 抚仙湖水体透明度呈下降趋势，从 1980 年平均 $7.9 \mathrm{~m}$ 降低至 2005 年的 $4.6 \mathrm{~m}$, 透明 度空间分布格局发生了显著变化, 这与抚仙湖水质污染的实际情况密切相关.

(4) 近 20 多年来, 抚仙湖藻类数量呈增长趋势, 特别是 2001 年以来增长速度加快, 平均密度是 1995 年前的 7 倍, 达 $119.25 \times 10^{4}$ ind./L. 藻类的增加阻碍了光线在水中的传播, 增加了光的衰减, 是影响透明度下 降的直接影响因子, 水体总氮、总磷的增长, 促进了藻类的增殖, 是透明度下降的重要间接影响因子.

\section{4 参考文献}

[1] 刘健康. 高级水生生物学. 北京: 科学出版社, 2000: 9-10.

[2] 李一平. 太湖水体透明度影响因子实验及模型研究. 南京: 河海大学, 2006: 181-192.

[3] 逢 勇, 李一平, 罗潋苟. 水动力条件下太湖透明度模拟研究. 中国科学(D 辑), 2005, 35(增刊 2): 145-156.

[4] 张运林, 秦伯强, 陈伟民等. 太湖水体透明度分布、变化及相关分析. 海洋湖沼通报, 2003, 96(2): 30-36.

[5] 杨顶田，陈伟民，曹文熙. 太湖梅梁湾水体透明度的影响因素分析. 上海环境科学, 2003, (增刊): 34-38.

[6] Bachmann RW, Hoyer MV, Canfield DE Jr. Evaluation of recent limnological changes at Lake Apopka. Hydrobiologia, 2001, 448: $19-26$.

[7] 赵碧云, 贺 涁, 朱云燕等. 滇池水体中透明度的遥感定量模型研究. 环境科学与技术, 2003, 26(2): 16-17.

[8] 张运林, 秦伯强, 陈伟民等. 太湖水体中悬浮物的研究. 长江流域资源与环境, 2004, 13(3): 266-271.

[9] 中国科学院南京地理与湖泊研究所编. 抚仙湖. 北京: 海洋出版社, 1990.

[10] 王苏民, 荬鸿身. 中国湖泊志. 北京: 科学出版社, 1998: 78.

[11] 李荫尔, 刘 红, 陆 娅等. 抚仙湖富营养化初探. 湖泊科学, 2003, 15(3): 285-288.

[12] 水和废水监测分析方法编委会. 水和废水监测分析方法(第四版). 北京：中国环境科学出版社, 2002. 